Portland State University

PDXScholar

1976

\title{
An exploratory study of the effects of parenting relationships on children's school adjustment
}

\author{
Raymond M. Lappin \\ Portland State University \\ Lisa J. Posner \\ Portland State University \\ Marcia S. Smith \\ Portland State University
}

Follow this and additional works at: https://pdxscholar.library.pdx.edu/open_access_etds

Part of the Child Psychology Commons, Social Welfare Commons, and the Social Work Commons Let us know how access to this document benefits you.

\section{Recommended Citation}

Lappin, Raymond M.; Posner, Lisa J.; and Smith, Marcia S., "An exploratory study of the effects of parenting relationships on children's school adjustment" (1976). Dissertations and Theses. Paper 1780. https://doi.org/10.15760/etd.1779

This Thesis is brought to you for free and open access. It has been accepted for inclusion in Dissertations and Theses by an authorized administrator of PDXScholar. Please contact us if we can make this document more accessible: pdxscholar@pdx.edu. 
AN EXPLORATORY STUDY OF THE

EFFECTS OF PARENTING RELATIONSHIPS

ON CHIIDREN'S SCHOOL ADJUSTMENT

by

Baymond M. Lappin

Iisa J. Posner

Marcia S. Smith

A research project submitted in partial fulfillment of the requirements for the degree of

MASTER OF SOCIAI WORK

Portland State University

1976 
TO THE OFFICE OF GRADUATE STUDIES AND RESEARCH:

The members of the Committee approve the research study of Raymond $M$. Lappin, Iisa J. Posner and Marcia S. Smith presented on May 26, 1976.

Jáy Conréb

Research Adviser 


\section{ACKNOWLEDGEMENTS}

We wish to express our special thanks and appreciation to Jay Conrad, our adviser, Nancy Koroloff of the Portland State University faculty, and to Nolan Jones and Stanley N. Cohen of the Impact of Divorce on Children and Their Parents Project (IDCAP) for their advice and assistance in preparing this research project. We would also like to thank our typist, Carol Barnett.

Finally, we wish to acknowledge the contribution of the parents and children who provided the basis of our research data. 
TABLE OF CONTENTS

PAGE

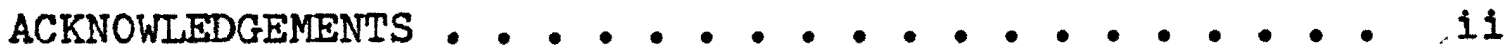

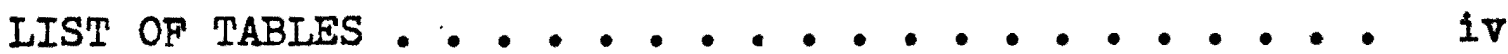

I. INTRODUCTION . . . . . . - . . . . 1

II. REVIEW OF THE IITERATURE . . . . . . . . . 4

III. METHODOLOGY ......... . . . . . 13

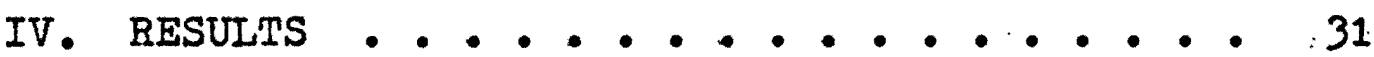

V. DISCUSSION OF THE RESULTS . • • • • • • 39

VI. IIMITATIONS ............... 44

VII. IMPIICATIONS FOR FURTHER RESEARCH • • • • 46

VIII. SUMMARY .. . . . . . . . . . . 50

IX. REFERENCES CITED . . . . . . . . . . 51

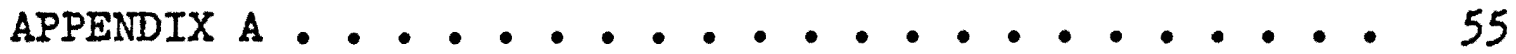

APPENDIX B . . . . . . . . . . . . . . . 58

APPENDIX C ....................... 59

APPENDIX D.... . . . . . . . . . . . . 61

APPENDIX E . . . . . . . . . . . . . . . . 62 


\section{IIST OF TABLES}

TABLE

PAGE

I. Adults' Education . . . . . . . . . 17

II. AduIts' Occupation .... .."...... 18

III. Church Attendance . . - . . . . . 19

IV. Characteristics of Children... . . . 20

V. Age in Relation to Agreement, Cooperation and Perception Scores ........ 33

VI. Education in Relation to Agreement,

Cooperation, and Perception

Scores ............. 34

VII. Church Attendance in Relation to

Agreement, Cooperation, and

Perception Scores .... . . . 34

VIII. Occupation in Relation to Agreement,

Cooperation, and Perception

Scores ..... . . . . . . 35

IX. Wives' Work History in Relation to

Agreement, Cooperation, and

Perception Scores . . . . . . 36

X. Birth Order of Chilaren in Relation to

Agreement, Cooperation, and

Perception Scores ... . . . . . . 
TABLE

PAGE

XI. Sex of Children in Relation to Agreement, Cooperation, and Perception Scores . . 37 


\section{INTRODUCTION}

As indicated in the National Vital statistics Report of April, 1973 (Volume 20, Number 22, pp. 16-19), the rate of divorces involving minor children is increasing rapidly in this country. Consequently, concern about the effects of divorce on children has been growing. In 1974, a collaborative effort between the clackamas County (Oregon) circuit Court and the Portland State University National Justice Educational Development Project was begun to study the impact of divorce on children and their parents (IDCAP). Heading the team of researchers are stanley N. Cohen, Ph.D., and Nolan Jones, Research Associate. Of special interest to Cohen and Jones is the parenting relationship of the couple, both before and after they filed for divorce. This relationship is seen as being directly related to the adjustment of the children: "The longer it takes to reestablish consistent parental relationships by divorcing couples, the more difficult it is for children to respond appropriately to the social and personal changes accompanying the divorce" (Cohen and Jones, 1974). Among the objectives which Cohen and Jones have Iisted is to provide "an 18-month longitudinal study of the extent to which parenting styles developed by couples prior to, during and after divorce impact on the behavior of their children." 
This practicum, done in cooperation with the IDCAP Project, is designed to look at the parenting relationships of couples before they filed for divorce and to assess the effect that this relationship had on their children's school behavior. Two key elements of the parenting relationship are seen as important to the adjustment of children (Cohen and Jones, 1974; Ferre1ra, 1963; Ferre1ra and Winter, 1965, 1969; and Riskin and Faunce, 1970). The first is agreement: the attitudes of the couple as revealed in what they say about child-rearing issues. The second is cooperation: the behavior of the couple as revealed in what they have done about child-rearing issues. In simple terms, agreement relates to thought and cooperation relates to action. In the case of divorcing parents, if they agree and cooperate with regard to their children prior to the divorce, then they are more likeIy to maintain an agreeing, cooperative parenting relationship subsequent to the divorce, thus easing the transition for their children in a time of extreme stress (Cohen and Jones, 1974). It also seems likely that an agreeing, cooperative parenting relationship in any family (i.e. nondivorcing couples as well) would provide a stable and consistent environment for children and would therefore enable these children to cope more readily with the stresses of life in general (Ferreira and Winter, 1965,1968, 1969; and Riskin and Faunce, 1970).

Although our study consists of a sample of divorcing parents and their children, we are not dealing with the 
diviorce issue per se. Rather, we are concerned with the parenting relationship of each couple in the two years before they filed for divorce. We are also looking at the school behavior of the eight to twelve year old children of these couples during that two year period (See Methodology). The children's behavior in school as determined by attendance, social behavior, study skills, and academic achievement are used to measure their adjustment. Although this study is descriptive, we assume that there may be a relationship between a child's school behavior and the degree of agreement and cooperation shown by his parents.

A third element of the parenting relationship, the perception of each of the parents about the other's childrearing attitudes and practices, is also introduced. It is assumed that the more accurately a couple perceives each other, the more effective their communication with one another. The more effective their communication, the greater their ability to be cooperative parents. Perception scores as well as agreement and cooperation scores were obtained for each couple. 


\section{REVIEW OF THE IITERATURE}

Today in our American society one out of every three marriages ends in a divorce. Rogers (1973), in his book Becoming Partners, acknowledges the failure of marriage as an American institution. The Parents Without Partners Organization is also an indication of the generality of the problem of divorce. The international office of Parents Without Partners reports the United States has the largest membership in its organization, followed by Canada and Australia (Sudia 1973, p. 309).

As mentioned, data reported in the National Vital Statistics Report (April 1973) Indicated both the number and proportion of divorcing families with minor children (those under the age of 18) have risen sharply over the past twenty years. For example, an estimated 840,000 minor children were involved in divorce in 1969 , as compared to 413,000 children in 1960, and 330,000 in 1953. In 1967, for only the second time in history, more than a million adults were involved in divorce actions, and in 1968, the figure was 1.2 million. The Mondale Committee on American Familles: Trends and Pressures (Congressional Record, September 1973) points to the trend continuing through the 70 's.

Rather than look at the effects of divorce itself, we chose to look at the effects of the parenting relationship 
on the children during the marriage. We were also concerned with the absence of research material on normal families, while the field appears to be well documented with studies on "clinic" or "sick" families. Therefore, our sample was drawn from the general population which may or may not have included families seeking help from a clinic.

It appears essential for researchers to take a first hand look at the issues surrounding marriage and divorce and their effects on the children who are products of these marriages .

Because of the terms used in the literature, the following definitions will apply in this discussion. A normal family is one in which no family member or members have been referred to an outpatient psychiatric facility or diagnosed through a formal diagnostic conference as suffering from a psychiatric disorder.

Abnormal, disturbed, clinic, or pathological families are ones in which one or more members have been referred to an outpatient psychiatric facility, and diagnosed through a formal diagnostic conference as suffering from a psychiatric disorder (psychotic, neurotic, schizophrenic, etc.).

We recognize that many "intact homes" might involve much more discordance than homes broken by separation and divorce. The legal event of divorce may undoubtedly be much less traumatic to all involved than the "emotional divorce" which inevitably preceeded it. It is difficult to ascertain how long disharmony has to last before the children of the 
marriage are affected, how permanent are the effects, and what sorts of disharmony are particularly associated with specific deviant behaviors or adjustment problems of the children. There is evidence that suggests that the longer the family disharmony lasts the greater the risk to the children. A lack of feeling and active discord in the family have been associated with deviant behavior in the children. Birtchell (1969), Cheek (1962, 1966), Tuckman and Regan (1967), Felner, Stolberg, and Cowen (1975) argued that separation and divorce more often follow a chronic, conflictladen overt process between the married couple. Birtchell (1969) further suggested that the delinquent behavior of the children of separated and divorced couples may reflect the parents' marital conflict and that the final act of separation or divorce merely exaggerates such behavior.

Gassner and Murray (1969) suggested that the development of pathological behavior in the child is related not only to emotional disturbances in the individual parents, but also to the disturbances in the relationship between parents which may affect the mode of functioning of the entire family.

Caputo (1963), Fisher, Boyd, Walker and Sheer (1953), Lennard (1965), Lennard and Bernstein (1969), and Mishler and Waxler (1966,1968a, 1968b) suggested there is a greater amount of conflict and less communication clarity in pathological families when compared to normal families. In the clinic families there tends to be more parental conflict and 
fewer means of resolving these conflicts because of the breakdown of communication in the clinic families.

A number of clinicians and students of the family have noted that lack of self-validation and frequent disagreements are distinguishing characteristics of disturbed families. The distribution of positive and negative reactions, whether conceived of as agreement/disagreement, confirmation/contradiction, congruence/incongmuence, or support/attack, can be considered to be significant characteristics of interaction in a social context, most especially in the family context (Lennard and Bernstein, 1969, p. 113-114).

Several investigators in the area of family interaction and psychopathology have begun to formulate models of disturbed and normal family functioning based on the results of empirical research. In particular, Ferreira (1963), Ferreira and winter $(1965,1966,1968,1969)$, Ferreira, winter and Poindexter (1966), Winter and Ferreira (1967, 1969) have evolved a model based upon the investigation of family decision-making in normal and abnormal families, with regard to such interaction process variables as spontaneous agreement (SA), decision time (DT), and choice fulfillment (CF), With noteworthy consistency, investigators of the process of family decision-making have discovered that some important differences exist between normal and abnormal families in the variables denoted as spontaneous agreement. 
Ferreira (1963), Ferreira and Winter (1965, 1968, 1969) suggested that spontaneous agreement occurs when two or more family members agree on the same choices when they individually fill in the unrevealed difference questionnaire. On the unrevealed difference questionnaire individual family members are asked to indicate their own personal preferences on the items on the questionnaire. What each individual had privately chosen on the questionnaire is not revealed to the other family members.

Bales (1950), Lennard and Bernstein (1969), Mishler and Waxler $(1966,1968)$, O'Connor and Stachowiak (1971), Riskin and Faunce (1964, 1970, 1972), Strodbeck (1951), and Vidich (1956) have used agreement - disagreement as major variabies in their research in the family interaction field.

Perreira (1963), Ferreira and Winter (1965, 1968, 1969) in their studies of family decision-making in normal and abnormal families found that abnormal families scored significantly lower on spontaneous agreement, longer on decision time, and lower on choice fulfillment, and proved to be less equipped for and less efficient for appropriate: decision-making. In contrast, normal families were shown to have much greater agreement among members prior to any exchange of information, spend less time in reaching a decision, and arrive at more appropriate decisions in terms of better fulfillment of the family members individual choices. Ferreiria (1966), in a study of the stability of the interactional variables in family decision-making, found the 
results to be consistent with earlier findings after a six month interval.

Murrell (1971) found that non-clinic ten to twelve year old boys with average functioning in areas of social acceptance and achievement belonged to a family system which was adequately organized to make decisions rapidly and which contained members who would pay attention and talk with one another equally rather than form coalitions. The family system was also characterized by shared communication of interests.

Faunce and Riskin (1970), Biskin (1964), and Biskin and Faunce $(1970,1972)$, in their evaluation of the family Interaction Scales to determine whether and how the scale categories discriminated among different family types (normal, multi-problem, and child-labeled problems), found that the families with the official child-labeled problems only, either acting out or underachiever, had the lowest agreement scores and the highest disagreement scores when contrasted with the other types of families.

To summarize the officlal child-labeled problem families: there is a low-keyed, sullen, argumentative, non-cooperative atmosphere in these families. They are muted, with a slight depressive tinge and with many. hints of underlying power struggles, not displaying much affect, and with very much disagreement (Riskin and Faunce, 1970; p. 534).

To summarize the normal families: there is much positive support, including parent-to-parent, parent-to-child, and child-to-parent. They are able to cooperate and provide a model for cooperation, and they agree with much forcefulness (Riskin and Paunce, 1970, p. 535). 
Alkire (1969) and Jacob (1974, 1975) suggested that the relationships among social class, child age and patterns of family dominance and conflict show a highly significant difference between parental disagreement scores as a function of social class status. That is, initial disagreement between parents was greater in lower-class families than in middle-class families. Agreement between parents was greater than parent-child agreement significantly more of ten in middle-class families than in lower-class families.

Schuham (1972) suggested that there was less spontaneous agreement manifested by families with a borderline psychotic child than in families with a non-psychotic child. Families with a borderline psychotic child appear to operate from a baseline of disagreement and more frequently fail to resolve their differences when given an opportunity to discuss them. It was found that parent-parent agreements outnumbered parent-child agreements in families with nonreferred children while parent-child agreements slightly outnumbered parent-parent agreements in families with referred children.

Gassner and Murray (1969) suggested that the interaction of parents of neurotic children in comparison with the interaction of parents of normal children show significantly more instances of disagreements between the parents of the neurotic children.

Riskin (1964), in his study of white, intact, midaleclass families, found the ratio of commitment to agreement 
for the fathers was quite low; that is, the father tends to agree with his spouse and other family members without committing himself. This suggests he tries to be agreeable.

Conclusions from the study of Mead and Campbel1 (1972) indicated that spontaneous agreement differentiates families with drug-using children from normal families just as it differentiates other abnormal family patterns such as maladjusted, delinquent, neurotic, and schizophrenic, in that normal families spontaneously agree more often than drug families.

Haley $(1964,1967,1968)$, Iennard and Bernstein (1969) and Singer and Wynne (1966) suggested that the verbal interaction patterns of disturbed family systems tended to manifest greater stress and imbalance along the agreement/ disagreement axis than did control families. They also concluded that in disturbed families there occurs considerably less verbal interaction between fathers and mothers.

The research reviewed in this report supports the notion that spontaneous agreement is a rather stable variable in families, and can differentiate normal from abnormal families. Ferreira and Winter (1969) concluded that decreased spontaneous agreement in abnormal families is an indication, relative to normal families, of a dearth of shared emotional experiences, less intensive, non-commital participation and decreased exchange of self-revealing information. It is often said that in abnormal families there is "no communication". It appears that their decrease in 
spontaneous agreement reflects their lack of communication and exchange of information among spouses and other family members. Decision-making and communication must be considerably more frustrating and less rewarding in abnormal as opposed to normal families. Thus, unhappiness, dissatisfaction with, and anger towards each other must occur to a greater extent in abnormal families. The feelings generated by the unhappiness, dissatisfaction, and anger in turn, likeIy lead to even greater difficulties in intra-family communication. It appears then that a lack of spontaneous agreement is an important element of a fundamental cycle of family pathology. An absence of spontaneous agreement can be seen both as a cause and effect of decreased intra-family agreement, cooperation, and communication. 


\section{METHODOLOGY}

The methodology employed in this study included (I) choosing a sample and describing its relevant characteristics, (2) developing, administering and scoring questionnaire which measures agreement, cooperation, and perception of divorcing couples, and (3) obtaining information on their children's school adjustment from data gathered by the IDCAP Project. Because-the IDCAP team had gathered school data going back two years before the parents' divorce filing, we chose this as the most feasible time period for our study.

\section{THE SAMPLE}

Our sample consisted of 18 couples with eight to twelve year old children who are participating in the IDCAP study. We chose this particular age group for the following reasons. First, it facilitated our obtaining information on the children's school adjustment for the two years prior to their parents' filing for divorce. Children younger than eight years old would not have school histories of two years, whereas children older than twelve would have junior high as well as elementary school records, which would make comparisons difficult. A second reason for this age group is that it corresponds to the latency period, a relatively quiescent period of growth, with fewer developmental crises than either 
the preschool or adolescent phases (Wenar, 1971). We therefore assumed that personal or social maladjustment during latency is more likely to be caused by difficulties within the family than by developmental crises, as during other stages. Furthermore, "because the child is relatively undisturbed by intense feeling, he is free to expand in other areas, such as academic learning, friendship, group activities, and social interests" (Wenar, 1971, p. 239). Since children's lives begin to center around peers and school at this age, we speculated that school adjustment might be an indicator of the degree of stress a child is experiencing in the home.

The fact that the couples in our sample were filing for divorce was not relevant to our research question. However, drawing our sample from the larger IDCAP population was extremely advantageous since we had limited time and resources. In addition, because our couples were already cooperating with the IDCAP research team, we hoped they would be likely to respond favorably to our request for additional information from them.

The IDCAP sample was drawn between June 17 and December 16, 1975. All couples with minor children filing for divorce in Clackamas County were contacted by the county circuit court judge and asked to cooperate with the researchers. 140 individuals (including 50 couples) comprised the final sample, and of these there were 24 completed couples (1.e. with data available from both spouses) who had children in the age 
range we selected for our study. Copies of our questionnaire were mailed to these 48 individuals, and were returned by 42 . Since we needed questionnaires from both members of each couple for our research purposes, we eliminated six single questionnaires, and were left with a final sample of $18 \mathrm{com}-$ pleted couples.

We obtained socio-economic information on our sample from data already gathered by the IDCAP Project. Two interviews had been conducted by IDCAP staff members with each individual in the sample. The first consisted of a written questionnaire followed by a taped interview, with the purpose of gathering background information on the couple and also information on their decision-making style around the issues of custody, child support, and visitation. The second interview, held six months later, expanded on the issues discussed in the first one and also focused on the progress of the parenting relationship during that six month period. our socio-economic data was obtained from the subjects' responses during these two interviews, and also from a copy of their petition for dissolution of the marriage on file at the IDCAP office.

Because the purpose of our study is descriptive, we did not hypothesize as to any possible relationships between our dimensions of agreement, cooperation and perception and any particular social, cultural and economic variables. Our choice of which of the latter variables to include was based on the data already gathered by IDCAP. We eliminated only 
those areas which seemed particularly irrelevant (such as work hisotry prior to the two year period we were interested in).

For several areas there was little or no variability within our sample. All but two of our 18 families had incomes of over $\$ 12,000$ a year, with the remaining two earning between $\$ 7,200$ and $\$ 12,000$. Our entire sample indicated their race as Caucasian. This was the first marriage for all the couples, and the first divorce filing for all but one, who were filing for the second time. Since the sample is so homogeneous for the above variables, no further treatment of this data was considered necessary. The age range of the 36 adults in our sample was from 29 to 51 years 01d. The majority were between 33 and 44 years of age, with six individuals age 45 to 51 , and nine age 29 to 32 . 
The highest educational level attained by the adults is shown in the following table:

\section{TABLE I}

ADULTS' 'EDUCATION

\begin{tabular}{|lcc|}
\hline & Husbands & Wives \\
Less than 4 years of high & 2 & 0 \\
school & 4 & 12 \\
High school diploma & 0 & 1 \\
Trade school & 5 & 2 \\
$1-3$ years of college & 6 & 3 \\
4 year college degree & 1 & 0 \\
Graduate degree & 18 & 18 \\
\hline \multicolumn{2}{c}{ Total } & \\
\hline
\end{tabular}

Table II illustrates the occupations, grouped into broad categories, of both husbands and wives. All 18 husbands held full-time jobs during the two years prior to divorce filing; three wives held full-time jobs, eleven were employed part-time, and four were not employed outside the home. 
TABIE II

ADULTS' OCCUPATION

\begin{tabular}{|lcc|}
\hline & Husbands & Wives \\
\cline { 2 - 3 } Professional-managerial & 7 & 2 \\
Office-clerical & 5 & 5 \\
Skilled labor & 3 & 1 \\
Unskilled labor & 3 & 6 \\
Not employed & 0 & 4 \\
\hline Total & 18 & 18 \\
\hline
\end{tabular}

Frequency of church or synagogue attendance of the adults in our sample is illustrated in Table III. (Although the numbers in the table would seem to indicate similar church-going habits among couples, this was not the case: in five couples one member attended religious services frequentIy, whereas his/her spouse did not attend at all.) 
TABLE III

CHURCH ATTENDANCE

\begin{tabular}{|ccc|}
\hline & $\frac{\text { Husbands }}{\text { No church attendance }}$ & $\frac{\text { Wives }}{7}$ \\
$\begin{array}{c}\text { Occasional attendance } \\
\text { (several times a year) }\end{array}$ & 3 & 3 \\
$\begin{array}{c}\text { Frequent attendance } \\
\text { (daily, weekly, or } \\
\text { monthiy) }\end{array}$ & 7 & 8 \\
\hline Total & 18 & 18 \\
\hline
\end{tabular}

Table IV provides a summary of relevant characteristics of the children in our sample. The ages indicated are not current, but were the children's ages at the time our data was gathered (December, 1975). 
TABIE IV

CHARACTERISTICS OF CHILDREN

\begin{tabular}{|c|c|c|c|c|}
\hline Family & $\begin{array}{l}\text { Children's } \\
\text { Age }\end{array}$ & Sex & School Grade & $\begin{array}{l}\text { Birth Order } \\
\text { of Children }\end{array}$ \\
\hline 1. & $\begin{array}{r}11 \\
8\end{array}$ & $\begin{array}{l}M \\
P\end{array}$ & $\begin{array}{l}6 \\
3\end{array}$ & $\begin{array}{l}\text { 1st of } 3 \\
\text { 2nd of } 3\end{array}$ \\
\hline 2. & 9 & $M$ & 4 & 1st of 2 \\
\hline 3. & $\begin{array}{l}12 \\
8 \\
8 \text { twins }\end{array}$ & $\begin{array}{l}\mathrm{F} \\
\mathrm{M} \\
\mathrm{F}\end{array}$ & $\begin{array}{l}7 \\
3 \\
3\end{array}$ & $\begin{array}{l}\text { ist of } 3 \\
\text { 2nd and } 3 \text { rd } \\
\text { of } 3\end{array}$ \\
\hline 4.. & 12 & $F$ & 7 & 1st of 2 \\
\hline 5. & 12 & $F$ & 7 & 2nd of 2 \\
\hline 6. & $\begin{array}{r}11 \\
9\end{array}$ & $\underset{\mathrm{F}}{\mathrm{M}}$ & $\begin{array}{l}6 \\
3\end{array}$ & $\begin{array}{l}\text { 1st of } 3 \\
\text { 2nd of } 3\end{array}$ \\
\hline 7. & 11 & $M$ & 6 & $4 \mathrm{th}$ of 4 \\
\hline 8. & 9 & $F$ & 4 & 1st of 2 \\
\hline 9. & 8 & $F$ & .. & 2 nd of 2 \\
\hline 10. & 12 & $\mathbf{M}$ & 7 & 5 th of 5 \\
\hline 11. & 8 & $M$ & 3 & 2 nd of 2 \\
\hline 12. & $\begin{array}{l}11 \\
10\end{array}$ & $\begin{array}{l}M \\
M\end{array}$ & $\begin{array}{l}5 \\
5\end{array}$ & $\begin{array}{l}\text { 1st of } 4 \\
\text { 2nd of } 4\end{array}$ \\
\hline 13. & 11 & $M$ & 5 & 3 rd of 3 \\
\hline 14. & 10 & $\mathrm{M}$ & 5 & 2 nd of 2 \\
\hline 15. & $\begin{array}{r}10 \\
8\end{array}$ & $\begin{array}{l}\mathrm{M} \\
\mathrm{F}\end{array}$ & $\begin{array}{l}5 \\
3\end{array}$ & $\begin{array}{l}\text { 1st of } 3 \\
\text { 2nd of } 3\end{array}$ \\
\hline 16. & 12 & M & 7 & $4 \mathrm{th}$ of 5 \\
\hline 17. & 12 & $F$ & 7 & 2nd of 4 \\
\hline 18. & $\begin{array}{l}11 \\
10\end{array}$ & $\mathrm{M}$ & $\begin{array}{l}6 \\
5\end{array}$ & $\begin{array}{l}1 \text { st of } 2 \\
\text { 2nd of } 2\end{array}$ \\
\hline
\end{tabular}


of the 25 children in our sample, 14 are boys and eleven girls. Nine are first-born children, seven are middle children, and the remaining nine are the youngest children in their families.

\section{THE QUESTIONNAIRE}

Constructing a questionnaire to measure agreement, cooperation and perception between marital partners on childrearing 1ssues was one of the major tasks of our research project. our reason for using a mailed questionnaire as opposed to a verbal interview was that the subjects had already participated in a lengthy tape-recorded interview with an IDCAP staff member and were not Iikely to welcome the prospect of another one. We wanted a quick and simple method of obtaining our data, and decided on a brief questionnaire accompanied by an explanatory cover letter. We hoped that one of the major shortcomings of mailed questionnaires, a low rate of return, would be minimized since the subjects had had prior contact with IDCAP. Copies of the final version of our questionnaire and cover letter are included in the appendices.

We limited the length of the questionnaire to a maximum of two pages, hoping our subjects would fill it out immediately upon receiving it. (A longer and more formidablelooking questionnaire would be more likely to be lost or 
misplaced.) We enclosed stamped self-addressed envelopes to further encourage a high rate of return.

In designing the questionnaire we kept several goals in mind. The most obvious one was to write questions which would clearly measure agreement, cooperation and perception as part of the parenting relationship between spouses. A second goal was to word our questionnaire in clear, concise, simple language which could be easily understood by all of our subjects. Our final goal was to construct the questionnaire in such a way as to facilitate the later task of scoring the results.

In order to get at agreement, cooperation and perception, we designed questions pertaining to two general areas of family functioning which involve the parenting relationship, discipline and recreational activities. These areas were chosen for several reasons. We assumed that: (1) they probably affect most children in the eight to twelve age group, (2) both mothers and fathers are likely to be involved, and (3) they involve typical everyday activities which may occur in most families regardless of class or culture. Two types of questions were included, which we labelled "general" and "situational" questions. General questions are concerned with the entire area of discipline or recreation, whereas situational questions describe a typical situation and ask the parent how he/she dealt with it. We assumed that the general questions would give us a more complete picture, but would be subject to the parent's biases or faulty memory; 
situational questions, on the other hand, while dealing with fairly limited subject areas, would force parents to be more accurate in their responses since a specific situation would be called to mind. We felt the two types of questions used together would be most likely to elicit complete and accurate information. Questions 1 through 5 cover the area of discipline; of these the first three are general questions, the last two situational ones (see questionnaire, Appendix A). Questions 6 through 10 deal with the area of recreational activities; questions $6,7,8$ are general and questions 9 and 10 are situational. At the end of the questionnaire we invite the subject to comment on the back of the page with any additional information, but none of the comments we received were particularly useful.

In addition to distinguishing between questions of the general and situational type, the questions may be divided into those that measure agreement, cooperation, and perception. We paid particular attention to the wording here, since it was vital for the respondent to distinguish between agreement, which has to do with attitudes and beliefs, and cooperation, which is concerned with actual behavior. Phrases such as "share the same ideas" (question 1) and "agree on the way the situation ought to be handled" (questions $4 \mathrm{~b}, 5 \mathrm{~b}, 9 \mathrm{~b}$, 10b) were intended to clearly indicate agreement/non-agreement. Phrases such as "satisfied with the way the situation actually was handled" (questions $4 c, 5 c$ ) were chosen to indicate the dimension of cooperation/non-cooperation. 
Perception is measured by questions such as, "Was your spouse satisfied?" $(4 d, 5 d)$, and "Would your spouse agree with your answer?" (3b). (To determine correct or incorrect perception the individual's response must be compared with his/her spouse's corresponding response).

It should be pointed out that we were not specifically interested in how parents dealt with particular situations (questions $4 a, 5 a, 9 a, 10 a$ ), but rather were interested in whether or not they agreed and cooperated with their spouses, regardless of how the situation was handled. We included part " $a$ " of questions 4, 5, 9 and 10 only to help stimulate the subject's memory, which hopefully increased the accuracy of his/her responses to parts "b", " $c$ " and " $d$ " which followed. (Parts " $b$ ", " $c$ " and " $d$ " of the situational questions measure, respectively, agreement, cooperation and perception).

Parents were requested in the cover letter to bear in mind several instructions while completing the questionnaire (see Appendix B). They were asked to answer the questions with regard to their eight to twelve year old children only, to think specifically of the two year period preceding the divorce filing, and to answer the questions in a general way, indicating how they usually felt or behaved (since their behavior might well have changed from one situation to the next over a two year period).

our questionnaire went through three revisions and an informal pre-test (using several friends and colleagues as 
subjects) before we were reasonably satisfied that we had achieved our objectives. The suggestions of our faculty adviser, of another interested faculty member, and of three IDCAP staff members were incorporated into the final version.

\section{SCORING THE QUESTIONNAIRE}

In developing a method of scoring the questionnaire, our goal was to give each couple separate scores for agreement, for cooperation, and for perception. Since agreement and cooperation imply a relationship between the two spouses, a single score was intended to encompass both spouses' responses for each of these areas. (Agreement score is abbreviated as AS, and cooperation score as CS.) Since perception implies one spouse's knowledge of the other's attitudes and practices, separate perception scores were given to husbands and wives. (Male perception score is abbreviated as MPS, female perception score as FPS.) A combined couple perception score (CPS) indicates the overall degree of correct perception of attitudes and practices for each couple.

A form for scoring each couple's questionnaire was developed (see Appendix $C$ ). On the first page, all questions which measure agreement and cooperation are indicated in the first column on the left. Questions which measure agreement are $1 a, 4 b, 5 b, 6,9 b$, and $10 b$. Cooperation questions are $2 a, 4 c, 5 c, 7 a, 8 a, 9 c$ and $10 c$. Checkmarks were entered in the columns marked A (for "agree"), DA (for "don't agree"), 
C (for "cooperate"), and DC (for "don't cooperate") for the male and female spouses of each couple.

The actual scoring process is indicated on page 3 of the scoring form. Using the agreement score as an example, we computed the ratio of "agree" responses to the total number of possible responses (twelve) by both husbands and wives to questions, dealing with agreement. Our rationale for such a score is illustrated by this simple formula:

$$
A S=\frac{A}{A+\frac{N R}{2}+D A+\frac{N R}{2}}
$$

$A=$ number of "agree" responses. $D A=$ number of "don't agree" responses. $\mathrm{NB}=$ number of questions with no response, or an unclear response.

Husbands' and wives' responses to the same question (which often differ) were thus given equal weight, since we assumed there was an equal chance that each of them was correct. That is, if the husband responded that the couple did not agree on a specific child-rearing issue, but the wife responded that they did agree, we assumed the husband or the wife could be correct and therefore weighted each response equally. Many subjects did not respond at all to some questions, possibly because they did not understand the question, because it didn't apply to them, or because they simply overlooked it. We again assumed there was an equal chance that agreement or non-agreement was in fact the case, and so entered one half the number of "no responses" (NR) on each 
side of the denominator. By this method the denominator always equaled twelve. By simply tallying the number of "agree" responses, dividing this figure by twelve, and converting it to a decimal figure, we arrived at a percentage score which indicates the extent of a couples' agreement as measured by their questionnaire responses.

The scoring process for cooperation is identical, except that the total number of possible cooperation responses (the denominator) is 14 . In this case the formula is:

$$
C S=\frac{C}{C+\frac{N R}{2}+D C+\frac{N R}{2}}
$$

On page 2 and the top of page 3 the questions dealing with perception are 1isted. There are a total of 16 possible responses, eight for the male spouse and eight for the female spouse. In this case the subjects' responses are not counted independently of each other, but rather must be checked against each other to determine correct or incorrect perception. For example, the male's response to question $2 a$ must agree with the female's response to $2 \mathrm{~b}$ in order to be counted as a correct perception. Similarly, the female's response to $2 a$ must coincide with the male's response to $2 \mathrm{~b}$. By entering checkmarks in the "yes" and "no" columns, correct and incorrect perception responses could be determined at a glance. 
Question 3 is scored somewhat differently, since it is different in structure than the other perception questions. A correct perception is indicated by a "yes" answer in part "b" if the two spouses' part " $a$ " responses are the same, and by a "no" answer if their part "a" responses are different. We arrived at the formulas used to score the perception items in the same way as for the agreement and cooperation scores. The denominator in the formula below is equal to eight.

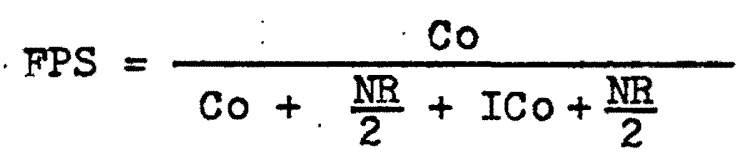

Co $=$ number of correct perception responses. ICo $=$ number of incorrect perception responses. $\mathrm{NR}=$ number of questions with no response or an unclear response.

The eight possible responses for the FPS are items 2, $3,5,7,9,11,13$ and 16 as indicated in the first column of pages 2 and 3 of the scoring sheet. The remaining eight items were used to calculate the MPS, and the CPS was based on all 16 perception items.

In summary, then, five separate percentage scores were computed for each of our 18 couples: an agreement score, cooperation score, male perception score, female perception score, and couple perception score. 
SCHOOL ADJUSTMENT

We obtained information from the IDCAP Project on the school adjustment of 16 of the 25 children in our sample. Unfortunately, as of this writing IDCAP had not yet gathered data on the remaining nine children. We had originally hoped to include data pertaining to the children's home adjustment as reported by their parents, but that data has not yet been compiled into usable form.

The school data was collected by several IDCAP staff members, who conducted taped interviews with each child's current teacher and also examined the children's school records. (Prior written consent was, of course, obtained from all parents.) The taped interviews were not useful for our purposes, since the teachers discussed only the child's current adjustment whereas we were interested in the two year period prior to filing. We were, therefore, forced to rely exclusively on the IDCAP interviewers' observations drawn from their examination of school records. These observations, usually consisting of teachers' quotes, were recorded on a special rating sheet (see Appendix D). We feel fairly confident that this data is as accurate and complete as could be gleaned from school records. Nevertheless; there are some methodological limitations to this part of our study which are discussed in a later section.

The IDCAP researchers divided school adjustment into four categories: health, social behavior, study skills, and 
academic performance. More specific descriptions of these broad areas are included on the rating sheet. For each area there are several teacher comments recorded, which include adjectives such as excellent, good, satisfactory, needs improvement, poor, and unsatisfactory (or equivalent phrases). We gave each child a score for each area based on a five point scale, ranging from no points for "unsatisfactory" to five points for "excellent". In the area of health the scores were based on number of days absent only, since few teacher comments pertaining to health were available. We derived our scores from the information recorded in columns two and three ("Iast school year" and "two years prior"), attempting to arrive at an average score if the child's adjustment appeared different for the two years. To insure reliability, two of our researchers worked independently of each other in scoring. each child's data sheet. They assigned the same scores in all but three cases, and reached agreement on those cases through discussion. Finally, a composite score was computed for each child, ranging from 0-20 points, by adding the four scores together. This score was then converted to a percentage. 


\section{RESULTS}

\section{QUESTIONNAIRE DATA}

As mentioned earlier, each of the 18 couples in our sample was given three scores: an agreement score (AS), a cooperation score (CS), and a couple perception score (CPS). The CPS was a composite of the female perception score (FPS) and the male perception score (MPS). Since there appeared to be no significant difference between the means of the female and male perception scores (mean FPS $=.54$ and mean MPS $=.52$ ), the composite score (CPS) was used for the rest of the study. (See Appendix E for a listing of all scores.)

The agreement scores ranged from .33 to 1.00 , with a mean of .65 and a mode of .67 . The AS was divided into three categories: high, medium, and low scores. The low scores ranged from 0 to .60; the medium scores were .61 to .70 ; the high scores were .71 to 1.00. This allowed for a fairly even distribution of couples in each category: six were low, seven were medium, and five were high.

Cooperation scores were treated in the same manner. The CS ranged from .21 to .93, with a mean of .61 and a mode of .64. The low category was 0 to .60 ; the medium was .61 to 
.70 ; and the high was .71 to 1.00 . There were seven couples in the low category, six in the medium, and five in the high. The couple perception scores ranged from 0 to .88 , with a mean of .55 and a mode of .63 . In the low category $(0$ to $.60)$, there were eight couples. Seven couples were in the medium $(.61$ to .70$)$, and three were high $(.71$ to 1.00$)$. Correlation coefficients were done between each of the three variables: agreement scores, cooperation scores, and couple perception scores. The correlation coefficient between AS and CS was .57. Between AS and CPS, the correlation coefficient was .53. The highest correlation was found between CS and CPS, .62.

\section{QUESTIONNAIRE DATA COMPARED TO SOCIO-ECONOMIC DATA}

Six major areas of socio-economic data were compared to agreement, cooperation, and perception scores: the age, education, church attendance, and occupation of each subject, the employment pattern (prior to filing for divorce) of each wife; and the birth order and sex of the eight to twelve year old children in our sample. (The employment pattern of the husbands was not included because all the husbands in our sample were employed full-time.) The age of the subjects was divided into three groups: a younger group, age 32 and younger, a middle group, ages 33 to 44 , and an older group, age 45 and older. (See Table V.) The majority of subjects (21 out of 36 individuals) fell into the middle group, as we 
thought might be the case with parents of eight to twelve year old children. (This is assuming that most people are between the ages of 20 and 30 when they have children.)

\section{TABLE V}

AGE IN RELATION TO AGREEMENT, COOPERATION AND PERCEPTION SCORES

\begin{tabular}{|ccccc|}
\hline Scores & Age & Agreement & Cooperation & Perception \\
\hline \multirow{2}{*}{ High } & 45 and older & 0 & 0 & 0 \\
$.71-1.00$ & 33 - 44 and younger & 5 & 5 & 2 \\
& 45 and older & 3 & 5 & 4 \\
Medium & 33 - 44 younger & 7 & 5 & 3 \\
$.61-.70$ & 32 and yound & 5 & 8 \\
& 45 and older & 3 & 1 & 3 \\
Low & 33 - 44 younger & 0 & 11 & 3 \\
$0-.60$ & 32 and young & 2 & 11 \\
\hline
\end{tabular}

Chi Square (significant at .10 level) between Age and Agreement was 8.79 .

Chi Square (significant at .10 level) between Age and Cooperation was 12.07 .

The subjects were divided into two groups on the basis of education, those who had gone as far as high school, and those who had gone beyond high school either to college or for further training: 
TABLE VI

EDUCATION IN RELATION TO AGREEMENT, COOPERATION, AND PERCEPTION SCORES

\begin{tabular}{|llccc|}
\hline Scores & Education & Agreement & Cooperation & Perception \\
\hline High & High School & 5 & 2 & 1 \\
$.71-1.00$ & College & 5 & 8 & 5 \\
Medium & High School & 6 & 8 & 9 \\
$.61-.70$ & College & 8 & 4 & 5 \\
Low & High School & 7 & 8 & 7 \\
$0-.60$ & College & 5 & 6 & 9 \\
\hline
\end{tabular}

Chi square (significant at .10 level) between Education and Cooperation was 5.21 .

Chi square (significant at .10 level) between Education and Perception was 5.86.

Church attendance was divided into three groups, frequent, occasional, and never:

\section{TABLE VII}

CHURCH ATTENDANCE IN RELATION TO AGREEMENT, COOPERATION, AND PERCEPTION SCORES

\begin{tabular}{|c|c|c|c|c|}
\hline Scores & $\begin{array}{c}\text { Church } \\
\text { Attendance }\end{array}$ & Agreement & Cooperation & Perception \\
\hline $\begin{array}{c}\text { High } \\
.71-1.00\end{array}$ & $\begin{array}{l}\text { Frequently } \\
\text { Occasionaliy } \\
\text { Never }\end{array}$ & $\begin{array}{l}6 \\
2 \\
2\end{array}$ & $\begin{array}{l}6 \\
3 \\
1\end{array}$ & $\begin{array}{l}4 \\
1 \\
1\end{array}$ \\
\hline $\begin{array}{l}\text { Medium } \\
.61-.70\end{array}$ & $\begin{array}{l}\text { Frequently } \\
\text { Occasionaliy } \\
\text { Never }\end{array}$ & $\begin{array}{l}5 \\
3 \\
6\end{array}$ & $\begin{array}{l}3 \\
2 \\
7\end{array}$ & $\begin{array}{l}4 \\
2 \\
8\end{array}$ \\
\hline $\begin{array}{l}\text { Low } \\
0.60\end{array}$ & $\begin{array}{l}\text { Frequently } \\
\text { Occasionaliy } \\
\text { Never }\end{array}$ & $\begin{array}{l}4 \\
1 \\
7\end{array}$ & $\begin{array}{l}6 \\
1 \\
7\end{array}$ & $\begin{array}{l}7 \\
3 \\
6\end{array}$ \\
\hline
\end{tabular}


The occupations of the subjects fell into five groups, professional-managerial, office-clerical, skilled labor, unskilied labor, and no employment:

TABIE VIII

OCCUPATION IN RELATION TO AGREEMENT, COOPERATION, AND PERCEPTION SCORES

\begin{tabular}{|c|c|c|c|c|}
\hline Scores & Occupation & Agreement & Cooperation & Perception \\
\hline $\begin{array}{c}\text { High } \\
.71-1.00\end{array}$ & $\begin{array}{l}\text { Professional- } \\
\text { Managerial } \\
\text { Office-Clerical } \\
\text { Skilled } \\
\text { Unskilled } \\
\text { Not Employed }\end{array}$ & $\begin{array}{l}1 \\
4 \\
2 \\
1 \\
2\end{array}$ & $\begin{array}{l}4 \\
3 \\
0 \\
1 \\
2\end{array}$ & $\begin{array}{l}1 \\
2 \\
0 \\
1 \\
2\end{array}$ \\
\hline $\begin{array}{l}\text { Medium } \\
.61-.70\end{array}$ & $\begin{array}{l}\text { Professional- } \\
\text { Managerial } \\
\text { Office-Clerical } \\
\text { Skilied } \\
\text { Unskilled } \\
\text { Not Employed }\end{array}$ & $\begin{array}{l}4 \\
4 \\
0 \\
6 \\
0\end{array}$ & $\begin{array}{l}3 \\
4 \\
3 \\
2 \\
0\end{array}$ & $\begin{array}{l}3 \\
5 \\
3 \\
2 \\
1\end{array}$ \\
\hline $0^{\text {Low }}-.60$ & $\begin{array}{l}\text { Professional- } \\
\text { Managerial } \\
\text { Office-clerical } \\
\text { Skilled } \\
\text { Unskilled } \\
\text { Not Employed }\end{array}$ & $\begin{array}{l}4 \\
2 \\
2 \\
2 \\
2\end{array}$ & $\begin{array}{l}2 \\
3 \\
1 \\
6 \\
2\end{array}$ & $\begin{array}{l}5 \\
3 \\
1 \\
6 \\
1\end{array}$ \\
\hline
\end{tabular}


The children were placed in groups for birth order (oldest, middle, youngest) and sex:

\section{TABLE $X$}

BIRTH ORDER OF CHILDREN IN REIATION TO AGREEMENT, COOPERATION, AND PERCEPTION SCORES

\begin{tabular}{|c|c|c|c|c|}
\hline Scores & Birth Order & Agreement & Cooperation & Perception \\
\hline $\begin{array}{c}\text { High } \\
.71-1.00\end{array}$ & $\begin{array}{l}\text { Oldest } \\
\text { Middle } \\
\text { Youngest }\end{array}$ & $\begin{array}{l}2 \\
2 \\
2\end{array}$ & $\begin{array}{l}2 \\
2 \\
3\end{array}$ & $\begin{array}{l}1 \\
1 \\
2\end{array}$ \\
\hline $\begin{array}{l}\text { Medium } \\
.61-.70\end{array}$ & $\begin{array}{l}\text { Oldest } \\
\text { Middle } \\
\text { Youngest }\end{array}$ & $\begin{array}{l}4 \\
3 \\
3\end{array}$ & $\begin{array}{l}2 \\
1 \\
3\end{array}$ & $\begin{array}{l}3 \\
3 \\
2\end{array}$ \\
\hline $0^{\text {Low }}-.60$ & $\begin{array}{l}\text { Oldest } \\
\text { Middle } \\
\text { Youngest }\end{array}$ & $\begin{array}{l}3 \\
1 \\
5\end{array}$ & $\begin{array}{l}5 \\
3 \\
4\end{array}$ & $\begin{array}{l}5 \\
2 \\
6\end{array}$ \\
\hline
\end{tabular}

TABLE XI

SEX OF CHILDREN IN RELATION TO

AGREEMENT, COOPERATION, AND PERCEPTION SCORES

\begin{tabular}{|ccccc|}
\hline Scores & $\begin{array}{c}\text { Sex of } \\
\text { Children }\end{array}$ & Agreement & Cooperation & Perception \\
\hline High & Male & 3 & 4 & 2 \\
$.71-1.00$ & Female & 3 & 3 & 2 \\
Medium & Male & 7 & 3 & 5 \\
$.61-.70$ & Female & 3 & 3 & 3 \\
Low & Male & 4 & 8 & 7 \\
$0-.60$ & Female & 5 & 4 & 6 \\
\hline
\end{tabular}


As shown in the tables, the groups in each area of socio-economic data were then compared to the high, medium, and low categories of agreement, cooperation, and perception scores. For example, of the ten subjects (five couples) with high cooperation scores, two had high school educations and eight went beyond high school. Such frequencies were obtained in all areas.

Based on this data, we chose eight areas to examine for possible relationships: agreement-age, agreement-church attendance, cooperation-age, cooperation-church attendance, cooperation-education, perception-age, perception-church attendance, perception-education. By using a chi square, the relationships between agreement and age, cooperation and age, cooperation and education, and perception and education were found to be significant at a $: 10$ level. (Cooperation-age was also significant at a .025 level.)

\section{QUESTIONNAIRE DATA AND SCHOOL DATA}

As indicated, school data was obtained on 16 children from 13 families. The children's scores ranged from .30 to .75, with a mean of .58. Correlation coefficients done between the children's school scores (CSS) and their parents' agreement, cooperation, and perception scores revealed no significant information. (The correlation between CSS and AS was -.04 ; between CSS and CS, it was .29; and between CSS and CPS, it was -.41.) This will be discussed more completely in the following section. 


\section{DISCUSSION OF THE RESULTS}

The positive correlations found between agreement and cooperation, agreement and perception, and cooperation and perception were moderately significant. The correlation between agreement and cooperation might have proved stronger with a sample of non-divorcing couples. We assume that there has been more conflict in a home where the parents file for divorce than in a home where the parents are "happily married." This marital conflict would probably affect the parenting relationship (i.e. agreement and cooperation). Therefore, we might expect more agreement and more cooperation among non-divorcing spouses. This, in turn, might lead to a stronger correlation between these two variables.

We did anticipate that a positive correlation would exist between agreement and cooperation in our sample. If a couple agrees on child-rearing issues and shares the same ldeas, then it will be easier for them to establish a cooperative parenting relationship. It is usually easier to work with someone when the two of you agree about what you are doing.

Our perception scores measured how correctly each spouse viewed what the other. was doing and thinking with regard to child-rearing issues. Perception may also have been affected by the sample of divorcing couples. Spouses in the 
process of a divorce often spend time reviewing the strengths and weaknesses of their relationship. Por this reason, they may have a more accurate perception of their relationship than they have had in previous years. Thus, perception scores of divorcing spouses could concelvably be higher than those of non-divorcing spouses. Of course, it is equally possible that the turmoil and conflict of divorce could cause perception between spouses to be less accurate. Either way, perception scores could be considerably influenced by the event of divorce. The correlations between agreement and perception and between cooperation and perception may then be either higher or lower for divorcing couples than nondivorcing couples. In other words, it is very difficult for us to draw any significant conclusions about the correlations done with our perception scores. In fact, we did find a positive correlation between perception and agreement and between perception and cooperation.

It is important to note that our agreement and cooperation data were obtained from a self-reporting questionnaire. Each subject was asked, "Did you and your spouse agree ... . ?" etc. If the subject had a poor perception score, then it is possible that his response to the agreement question was incorrect. That is, the subject might have perceived that he and his spouse did agree when in fact, they did not. The same would be true of cooperation questions. We did not control for this problem, but with a larger sample we might simply have eliminated the data for couples with low 
perception scores. We would then have had good reason to believe that the subjects' reports of their agreement and cooperation were correct, and our data might have proved more accurate.

Among the socio-economic data, education and age were found to be related to variables of the parenting relationship. The influence of education may be related to the couples' ability to communicate. For instance, if we assume that a college-educated couple has read more on child-rearing and has talked with more people who have varying philosophies on child-rearing than a high school-educated couple, then we might hypothesize that the college-educated couple would have greater knowledge of child-rearing practices. This knowledge might then serve as a bank of information from which the couple could draw for their communication on child-rearing issues, thus facilitating the communication and making it more effective. It is also possible that the higher the couple's education, the greater their verbal skills and the more effective their communication on child-rearing issues. Again, we assume that effective communication may help a couple maintain a cooperative parenting relationship. However, we recognize an equal possibility that education may not promote effective communication. Communication involves more than knowledge and verbal ability. To be effective, it also requires clear expression of thoughts and 
careful listening. These factors are not implicit in a college education.

The results obtained with regard to age and cooperation and agreement are less clear. Although there appears to be a relationship between age and $A S$ and $C S$, we are not certain as to the nature of the relationship or the reasons for its existence. Obviously, this needs to be explored in greater depth with a more comprehensive study.

Our school data was notably poor (see Iimitations), and therefore we were not surprised to find that our results in this area were inconclusive. No relationship appeared to exist between school behavior and the parenting relationship. In fact, siblings had markediy different school scores, which would not be the case if the parenting relationship were the important independent variable. Even with good data, school behavior alone is an inadequate measure of a child's adjustment. The behavior could be the result of many factors including poor teachers, learning disabilities, etc. Data from the parents about the child (in addition to school data) would have provided a more balanced, and probably more accurate, picture of the child's overall adjustment. of course, any influences which may have affected the parents' agreement, cooperation, and perception scores (such as the sample of divorcing couples) would have affected the possible relationship between those scores and the children's school behavior. It is also true that there simply: may be no 
relationship between parents' agreement and cooperation on child-rearing issues and their children's behavior. However, we believe that there still may be a relationship, but that our data was inadequate to show it. We will be interested to see if the IDCAP Project is able to obtain more conclusive evidence on these issues. 


\section{IIMITATIONS}

There are limitations involved in this study, as are inherent in any research undertaking.

Although our connection with the IDCAP Project was beneficial in some ways, it posed certain problems as well. Because the Project was somewhat behind schedule, we were not able to obtain home adjustment data on any of the children, or school adjustment data on five families.

We feel one of the major limitations of our study was the small size of the sample. Also, as we have mentioned elsewhere, a sample of non-divorcing couples would have been desirable.

The questionnaire was Iimited in several ways. Because we asked the subjects to reflect back over a two year period, the validity of our data was dependent on the accuracy of their recall. It is also possible that the subjects ignored this request entirely, basing their responses on present attitudes and behavior. The accuracy of many subjects' responses may have been affected by our restriction of the response categories to "yes" and "no". Often a more appropriate response is "sometimes". However, the use of a forced-choice did simplify the task of interpreting the data. As is possible with any mailed questionnaire, some subjects may have misinterpreted questions. This problem could have 
been reduced through more extensive pre-testing. The school data was severely limited by the subjectivity of the teachers who commented on the children, by the selectivity of the interviewers who obtained the data, and by our own bias in rating the data that was arailable. Direct observation of the children with a behavioral rating scale would have provided more objective, and possibly more complete information on each child. 


\section{IMPLICATIONS FOR FURTHER RESEARCH}

We strongly believe that further research in the area of parenting relationships is indicated. Due to the various methodological limitations which have just been discussed, most of our results are inconclusive. We still feel, however, that our basic assumption that agreement, cooperation and perception between marital partners influences their children's adjustment is a valid one, and that future research might well support it.

Our population by necessity was limited to divorcing couples, but we hope that future study of this issue will focus on randomly selected non-divorcing couples. In our investigation of the relationships between agreement, cooperation and perception and selected socio-economic variables, our results pointed to age and education as possibly significant. Additional research with a larger and less homogeneous population might corroborate these relationships, and uncover others as well. Because our sample was particularly homogeneous with regard to race and social class as defined by income, we did not investigate these factors, nor did we look at religious preference or mural vs. urban residence. It is conceivable that any or all of these variables might be related to agreement, cooperation or perception. 
Unfortunately, our attempt to demonstrate a positive correlation between parents' agreement, cooperation and perception and their children's school adjustment yielded no significant results. We see a need for additional research using more complete and accurate school adjustment data, as well. as data on children's adjustment in other areas (at home with parents and siblings, with peers in the neighborhood, etc.). We are also interested in the extent to which the parenting relationship influences the adjustment of children in other age groups. Are there developmental stages during which children are particularly sensitive to their parents' attitudes and behavior pertaining to child-rearing?

In assessing the extent of parents' agreement and cooperation we focused on discipline and recreation, since we felt these areas were appropriate for our sample of eight to twelve year old children. Other child-rearing areas might profitably be studied, both for this age group and especially for other age groups (since other areas might be of greater concern with younger or older children).

A related question is: to what extent does parental agreement and cooperation depend on the child-rearing area studied? It might be demonstrated that certain areas, such as discipline, are surrounded by greater strife than others, such as health matters. Not only might agreement and cooperation vary depending on the child-rearing issue, but they might also vary according to the children's age. Perhaps the 
difficulties of caring for a young infant or of dealing with a rebellious adolescent lead to less parental agreement and cooperation than exists at other stages of child development. The dimensions of agreement and cooperation need to be studled as dependant variables, influenced by a variety of different factors, as well as independent variables which impact on children's adjustment.

A broader research question which might be addressed is that of placing the parenting relationship in the context of the total marital relationship. Is there any correlation between agreement, cooperation and perception with regard to parenting issues and the same three dimensions with regard to finances, sexual relations, or social life? A further issue is that of changes in the marital relationship as spouses proceed through the developmental stages of adulthood. Does. the parenting relationship change over time, and if $\mathrm{so}$, in what way? (our data suggests that older couples might be less likely to agree on child-rearing issues than younger ones.) Because of the suggested significance of communication in several of our findings, we feel it would be useful as well to look at how communication in the marital relationship might affect agreement, cooperation and perception. Many of these questions might ideally be explored through a longitudinal study which would follow couples and their children over a number of years, preferably from the children's birth to adulthood, focusing on a variety of 
child-rearing issues. Not only would the effects of the parenting relationship on children's adjustment be investigated, but it would also be possible to turn the question around, exploring how children's behavior might affect the parenting relationship. 


\section{SUMMARY}

This study was designed to explore the effect which the parenting relationship of a couple, as measured by their agreement and cooperation on child-rearing issues, may have on their children's behavior. The sample consisted of 18 divorcing couples from Clackamas County and their eight to twelve year-old children. A questionnaire was sent to each of the parents to determine their agreement and cooperation on issues involved in child-rearing. The accuracy of each subject's perception of his spouse's child-rearing attitudes and practices was also examined. Additional socio-economic data on each couple was obtained from the Impact of Divorce on Children and Their Parents Project at Portland State University. Data from the children's schools provided information on their behavior and adjustment.

The results showed no clear relationship between parents' agreement and cooperation and children's school beharior. Agreement, cooperation, and perception each appear to have some positive correlation with one another. Education and age also seem to be related to factors in the parenting relationship. Implications for future research are discussed. 


\section{REFERENCES CITED}

Alkire, A.A. Social Power and Communication Within Families of Disturbed and Non-Disturbed Preadolescents. Journal of Personality and Social Psychology, 13: 334-349, 1969.

Bales, R.F. Interaction Process Analysis. Cambridge, Mass., Addison-Wesley Press Inc., 1950.

Birtchill, J. The Possible Consequences of Early Parent Death. British Journal of Psychiatry, 42: 1-12, 1969.

Caputo, D.V. The Parents of the Schizophrenic. Family Process, 2: 339-356, 1963.

Cheek, F.E. Family Interaction With Schizophrenics. New York, Columbia University Press, 1962.

Cheek, F.E. Family Socialization Techniques and Deviant Behavior. Family Process, 5: 199-217, 1966.

Cohen, S.N. and Jones, N. Impact of Divorce on Children and Their Parents, unpublished manuscript, 1974.

Faunce, E.E. and Riskin, J. Family Interaction Scales II: Data Analysis and Findings. Archives of General Psychiatry, 22: $513-526,1970$.

Felner, R., Stolberg, A, and Cowen, E. Crisis Events and School Mental Health Beferral Patterns of Young Children. Journal of Consulting and Clinical Psychology, 43: 305-310, 1975 .

Ferreira, A.J. Decision-Making in Normal and Pathological Families. Archives of General Psychiatry, 8: 68-73, 1963.

Ferreira, A.J. Stability of Interactional Variables In Family Decision-Making. Archives of General Psychiatry, 14: $352-355,1966$.

Ferreira, A.J. and Winter, W.D. Family Interaction and Decision-Making. Archives of General Psychiatry, 13: $214-233,1965$. 
Ferreira, A.J. and Winter, W.D. Information Exchange and Silence in Normal and Abnormal Families. Family Process, 7: 251-276, 1968 .

Ferreira, A.J. and Winter, W.D. Decision-Making in Normal and Abnormal Two-Child Families. Family Process, 7: $17-36,1969$.

Ferreira, A.J. and Winter, W.D. and Poindexter, E.J. Some Interactional Variables In Normal and Abnormal Families. Family Process, 5: 65-70, 1966.

Fisher, S., Boyd, I., Walker, D. and Sheer, D. Parents of Schizophrenics, Neurotics, and Normais. Archives of General Psychiatry, 1: 149-166, 1959.

Gassner, S. and Murray, E.J. Dominance and Conflict in Interaction Between Parents. Journal of Abnormal Psychology, 74: 33-41, 1969.

Haley, J. Research on Family Patterns: An Instrument Measurement. Family Process, 3: 41-65, 1964.

Haley, J. Experiments with Abnormal Families. Archives of General Psychiatry, 17: 53-63, 1967 .

Haley, J. Testing Parental Interactions of Schizophrenic and Normal Children. Journal of Abnormal Psychology, 73: $559-565,1968$.

Jacob, T. Patterns of Family Conflict and Dominance as a Function of Child Age and Social Class. Developmental Psychology, 10: 1-12, 1974.

Jacob, T. Family Interaction in Disturbed and Normal Families. Psychological Bulletin, 82: 33-65, 1975.

Lennard, H.I. Interaction in Families with a Schizophrenic Child. Archives of General Psychiatry, 12: 166-183, 1965.

Lennard, H.I. and Bernstein, A. Patterns in Human Interaction. San Francisco, Jossey-Bass, 1969.

Mishler, E.G. and Waxler, N.E. Family Interaction and Schizophrenia. Archives of General Psychiatry, 15: $64-74,1966$.

Mishler, E.G. and Waxler, N.E. Interaction in Families. New York, John Wiley and Sons Inc., 1968. 
Murrell, S. Family Interaction Variables and Adjustment in Non-Clinic Boys. Child Development, 42: 1485-1494, 1971.

National Vital Statistics Report, 20: 16-19, 1973.

O'Connor, W.A. and Stachowiak, J.G. Patterns of Interaction in Families with High Adjusted, Low Adjusted, and Mentally Retarded Members. Family Process, 10: 229-241, 1971.

Riskin, J. Family Interaction Scale: A Preliminary Report. Archives of General Psychiatry, 11: 484-494, 1964.

Riskin, J. and Faunce, E.E. Family Interaction Scales I. Archives of General Psychiatry, 22: 504-512, 1970.

Riskin, J. and Faunce, E.E. Family Interaction Scales III. Archives of General Psychiatry, 22: 527-537, 1970.

Riskin, J. and Faunce, E.E. An Evaluative Review of Family Interaction Besearch. Family Process, 11: $365-456,1972$.

Rogers, C. Becoming Partners: Marriage and Its Altematives. New York, Delacorte Press, 1973.

Schuham, A. Activity; Talking Time, and Spontaneous Agreement in Disturbed and Normal Family Interaction. Journal of Abnormal Psychology, 79: 68-75, 1972.

Singer, M.T. and Wynne, I.C. Principles of Scoring Communication Defects and Deviances in Parents of Schizophrenics. Psychiatry, 29: 260-288, 1966.

Strodbeck, F.I. Husband-Wife Interaction Over Revealed Differences. American Sociological Review, 16: 468-473, 1951.

Sudia, C. An Updating and Comment on the United States Scene. Family Coordinator, 22: 309-312, 1973.

Tuckman, J. and Regan, R. Intactness of the Home and Behavioral Problems in Children. Journal of Child Psychology and Psychiatry, 7: 225-233, 1966.

U.S. Congress. American Families: Trends and Pressures. Hearings before the Senate Subcommittee on Children and Youth. Congressional Record, 119 (SeptemberOctober), 1973. 
Vidich, A. Methadological Problems in the Observation of Husband-Wife Interaction. Marriage and Family Living, 18: $234-239,1956$.

Waxler, N.E. and Mishler, E.G. Sequential Patterning of Family Interaction with Schizophrenic Children and Well Siblings. Archives of General Psychiatry, 25: 223-231, 1971.

Wenar, C. Personality Development. Boston, Houghton-Mifflin Co., 1971.

Winter, W.D. and Ferreira, A.J. Interaction Process Analysis of Family Decision-Making. Family Process, 6: 155-172, 1967.

Winter, W.D. and Ferreira, A.J. Research in Family Interaction: Palo Aito, California, Science and Behavior Books, 1969. 


\section{APPENDIX A \\ QUESTIONNAIRE}

ID Na.

1a. Did you and your spouse generally share the same ideas regarding the discipline of your child? yes no

2a. Were you satisfied with the way discipline was actually carried out? yes no

b. Was your spouse satisfied? yes. no

3a. Who most frequently disciplined your child? you your spouse both

b. Would your spouse agree with your answer? yes no

4a. When your child did not complete his homework assignment on time, what usually happened? Check one: nothing was done

- child was punished

- the situation never occurred

- other (please explain)

b. Did you and your spouse agree on the way the situation ought to be handled? yes no

c. Were you satisfied with the way the situation actualiy was handled? yes no

d. Was your spouse satisfied? yes no 
5a. When your child did not complete an assigned household chore, what usually happened? Check one:

nothing was done
request was repeated
child was punished
reasoned with child
the situation never occurred
other (please explain)

b. Did you and your spouse agree on the way the situation ought to be handled? yes no

c. Were you satisfied with the way the situation actualiy was handled? yes no

d. Was your spouse satisfied? yes no

6a. Did you and your spouse generally agree about the amount of time parents should spend with their children in recreational activities? yes no

7a. Were you generally satisfied with the amount of time you spent with your child in recreational activities? yes no

b. Was your spouse satisfied with the amount of time you spent? yes no

8a. Were you satisfied with the amount of time your spouse spent with your child in recreational activities? yes no

b. Was your spouse satisfied with the amount of time he/she spent? yes no 
9a. What usually happened when parents were invited to your child's activities? (For example, a baseball game or a school play). Check one:

\section{you attended}

your spouse attended

both attended together

neither attended

sometimes you attended, sometimes your spouse attended the situation never occurred other (please explain)

b. In the above situation, did you and your spouse agree about what ought to happen? yes no

c. Were you satisfied with what actually happened? yes no

d. Was your spouse satisfied? yes no

10a. What usually happened when one member of your family suggested an outing? (For example, a picnic or a movie).
you went with your children your spouse went with your children
- you and your spouse both went
— there was no outing
- the situation never occurred
- other (please explain)

b. In the above situation, did you and your spouse agree about what ought to happen? yes no

c. Were you satisfied with what actually happened? yes no

d. Was your spouse satisfied? yes no

If you wish to comment, please use the back of the questionnaire. (Were the questions clear to you? Is there additional information you consider important?) 


\author{
APPENDIX B
}

COVER LETTER

December 28,1975

Dear Parent,

You have previously completed a questionnaire and an interview for the Impact of Divorce on Children and their Parents (IDCAP) study. We would now like to ask your cooperation in providing us with some additional information. As before, this information is considered confidential.

Enclosed is a short questionnaire which we would like you to complete and return to us by January 15, 1976. Please keep the following in mind while answering the questions:

1. This questionnaire is limited to the two years before you and your spouse separated. Answer the questions with regard to that time period alone. (If you and your spouse are still living together, answer the questions with regard to the two years before you filed for divorce). the time.

2. In your responses, think of how you felt most of

3. We are limiting this part of the study to children in the eight to twelve year old age range. Answer the questions for your child of that particular age.

4. If you have additional comments, please write them on the back of the questionnaire.

Thank you so much for your help!

Sincerely,

Marcia Smith

IDCAP Project 


\section{APPENDIX C}

SCORING SHEET

AGREEMENT-COOPERATION

\begin{tabular}{|c|c|c|c|c|c|}
\hline Question & Respondent & A & $\mathrm{DA}$ & C & DC \\
\hline $1 \mathrm{~A}$ & $\begin{array}{l}\mathrm{M} \\
\mathrm{P}\end{array}$ & & & & \\
\hline $2 \mathrm{~A}$ & $\begin{array}{l}M \\
F\end{array}$ & & & & \\
\hline $4 B$ & $\begin{array}{l}\mathrm{M} \\
\mathrm{F}\end{array}$ & & & & \\
\hline $4 C$ & $\begin{array}{l}M \\
F\end{array}$ & . & & & \\
\hline $5 B$ & $\frac{M}{F}$ & 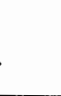 & & & \\
\hline $5 C$ & 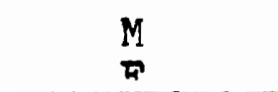 & & & & \\
\hline 6 & $\begin{array}{l}M \\
F\end{array}$ & & & & \\
\hline $9 B$ & $\begin{array}{l}M \\
\mathrm{~F}\end{array}$ & & & & \\
\hline $9 \mathrm{C}$ & $\begin{array}{l}M \\
F\end{array}$ & & . & & \\
\hline $10 B$ & $\begin{array}{l}M \\
F\end{array}$ & & & & \\
\hline $10 \mathrm{C}$ & $\underset{F}{M}$ & & & & \\
\hline $\begin{array}{l}7 \mathrm{~A} \\
8 \mathrm{~A} \\
7 \mathrm{~A} \\
8 \mathrm{~A} \\
\end{array}$ & $\begin{array}{l}M \\
F \\
M \\
M\end{array}$ & & & & . \\
\hline
\end{tabular}


PERCEPTION

\begin{tabular}{|c|c|c|c|c|}
\hline Item & Respondent & Question & Yes & No \\
\hline$\overline{1 .}$ & $\begin{array}{l}\mathrm{M} \\
\mathrm{F}\end{array}$ & $\begin{array}{l}2 \mathrm{~A} \\
2 \mathrm{~B}\end{array}$ & & \\
\hline 2. & $\begin{array}{l}\mathrm{F} \\
\mathrm{M}\end{array}$ & $\begin{array}{l}2 \mathrm{~A} \\
2 \mathrm{~B} \\
\end{array}$ & & \\
\hline 3. & $\begin{array}{l}\bar{M} \\
F\end{array}$ & $\begin{array}{l}4 C \\
4 D\end{array}$ & & \\
\hline 4. & M & $\begin{array}{l}4 C \\
4 D\end{array}$ & & \\
\hline 5. & $\begin{array}{l}\mathrm{M} \\
\mathrm{F}\end{array}$ & $\begin{array}{l}5 \mathrm{C} \\
5 \mathrm{D}\end{array}$ & & \\
\hline 6 & $\begin{array}{l}7 \\
M\end{array}$ & $\begin{array}{l}5 \mathrm{C} \\
5 \mathrm{D}\end{array}$ & & \\
\hline 7. & M & $\begin{array}{l}8 \mathrm{~A} \\
7 \mathrm{~B}\end{array}$ & & \\
\hline 8. & $\vec{M}$ & $\begin{array}{l}8 \mathrm{~A} \\
7 \mathrm{~B}\end{array}$ & & \\
\hline 9 & $\begin{array}{l}\bar{M} \\
F\end{array}$ & $\begin{array}{l}7 \mathrm{~A} \\
8 \mathrm{~B}\end{array}$ & & \\
\hline 10 & $\begin{array}{l}\text { F } \\
\text { M }\end{array}$ & $\begin{array}{l}7 \mathrm{~A} \\
8 \mathrm{~B}\end{array}$ & & \\
\hline 11. & $\begin{array}{l}\bar{M} \\
F\end{array}$ & $\begin{array}{l}9 C \\
9 D\end{array}$ & & \\
\hline 12. & $\begin{array}{l}F \\
M\end{array}$ & $\begin{array}{l}9 C \\
9 D \\
\end{array}$ & & \\
\hline 13. & $\begin{array}{l}\bar{M} \\
\mathrm{~F}\end{array}$ & $\begin{array}{l}10 \mathrm{C} \\
10 \mathrm{D}\end{array}$ & & \\
\hline 14. & $\begin{array}{l}\text { F } \\
M\end{array}$ & $\begin{array}{l}10 C \\
10 D \\
\end{array}$ & & \\
\hline
\end{tabular}

Question \#3

\begin{tabular}{|l|l|l|l|}
\hline Item & Respondent & \multicolumn{2}{c|}{ Part A } \\
\hline & $\begin{array}{c}\text { Same } \\
\text { Response }\end{array}$ & $\begin{array}{l}\text { Different } \\
\text { Response }\end{array}$ & Yes \\
15. & $\mathrm{M}$ & & \\
16. & $\mathrm{~F}$ & & \\
\hline
\end{tabular}


Scoring:

Agreement

$\begin{array}{cc}\mathrm{A}=- & \mathrm{C}= \\ \mathrm{DA}= & \mathrm{DC}= \\ \mathrm{NR}= & \mathrm{NR}= \\ \mathrm{AS}= & \mathrm{CS}=\end{array}$

Cooperation

$C S=$

\begin{tabular}{|c|c|}
\hline \multicolumn{2}{|c|}{ Perception } \\
\hline $\begin{array}{c}\text { Male } \\
\text { Co }=\end{array}$ & $\begin{array}{c}\text { Femal } \\
\text { Co }=\end{array}$ \\
\hline$I C O=$ & $I C O=$ \\
\hline $\mathrm{NR}=$ & $\mathrm{NB}=$ \\
\hline MPS $=$ & FPS $=$ \\
\hline
\end{tabular}


APPENDIX D

SCHOOL ADJUSTMENT

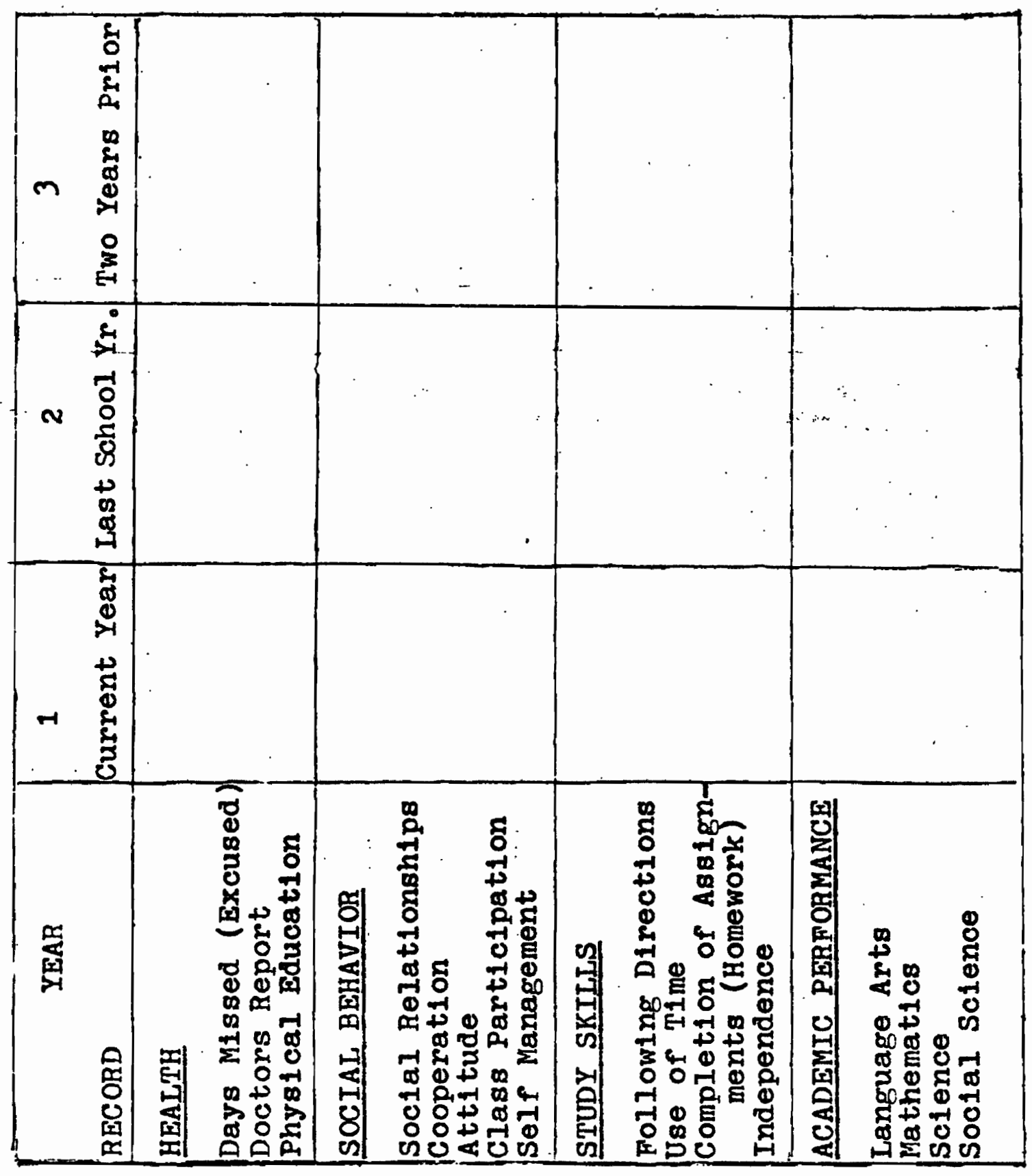




\section{APPENDIX E}

OVERAIT SCORES

\begin{tabular}{|ccccc|}
\hline Family & Agreement & Cooperation & Perception & $\begin{array}{c}\text { School } \\
\text { Adjustment }\end{array}$ \\
\hline 1. & $.67(\mathrm{M})$ & $.21(\mathrm{I})$ & $.50(\mathrm{I})$ & - \\
2. & $.83(\mathrm{H})$ & $.64(\mathrm{M})$ & $.69(\mathrm{M})$ & .60 \\
3. & $.42(\mathrm{I})$ & $.43(\mathrm{I})$ & $.13(\mathrm{I})$ & - \\
4. & $.67(\mathrm{M})$ & $.64(\mathrm{M})$ & $.63(\mathrm{M})$ & .75 \\
5. & $.58(\mathrm{I})$ & $.64(\mathrm{M})$ & $.63(\mathrm{M})$ & .45 \\
6. & $.67(\mathrm{M})$ & $.86(\mathrm{H})$ & $.44(\mathrm{I})$ & - \\
7. & $.58(\mathrm{I})$ & $.64(\mathrm{M})$ & $.63(\mathrm{M})$ & - \\
8. & $.33(\mathrm{I})$ & $.29(\mathrm{I})$ & $.31(\mathrm{I})$ & .70 \\
9. & $.75(\mathrm{H})$ & $.79(\mathrm{H})$ & $.81(\mathrm{H})$ & .65 \\
10. & $.67(\mathrm{M})$ & $.64(\mathrm{M})$ & $.44(\mathrm{I})$ & - \\
11. & $.67(\mathrm{M})$ & $.71(\mathrm{H})$ & $.50(\mathrm{I})$ & .50 \\
12. & $.67(\mathrm{M})$ & $.57(\mathrm{I})$ & $.63(\mathrm{M})$ & .70 \\
13. & $.67(\mathrm{M})$ & $.43(\mathrm{I})$ & $.0(\mathrm{I})$ & .50 \\
14. & $.75(\mathrm{H})$ & $.79(\mathrm{H})$ & $.81(\mathrm{H})$ & .75 \\
15. & $1.00(\mathrm{H})$ & $.93(\mathrm{H})$ & $.88(\mathrm{H})$ & - \\
16. & $.50(\mathrm{I})$ & $.57(\mathrm{I})$ & $.63(\mathrm{M})$ & .40 \\
17. & $.92(\mathrm{H})$ & $.64(\mathrm{M})$ & $.63(\mathrm{M})$ & .55 \\
18. & $.33(\mathrm{I})$ & $.57(\mathrm{I})$ & $.56(\mathrm{I})$ & .70 \\
\hline
\end{tabular}

Couple Scores:

$$
\begin{aligned}
& H=\operatorname{High}(.71-1.00) \\
& \mathrm{M}=\operatorname{Midium}(.61-.70) \\
& \dot{I}=\operatorname{Low}(0-.60)
\end{aligned}
$$

